\title{
Barriers to Interpersonal Communication as a Tool for Improving the Uptake of Voluntary Medical Male Circumcision in Siaya County, Kenya
}

\author{
Osir Otteng $^{1 *} \quad$ Peres Wenje $^{1} \quad$ Michael Kiptoo $^{2}$ \\ 1. School of Arts and Social Sciences, Masinde Muliro University of Science and Technology, P.O. Box 190- \\ 50100, Kakamega, Kenya \\ 2. Management Board, Kenya Medical Training College, Off Ngong Road, P.O. BOX 30195-00100, Nairobi,
} Kenya

\begin{abstract}
Despite its acknowledged importance in health management, particularly when dealing with such sensitive issues that transcend the boundaries of health as sexuality, stigma and discrimination, there is little research on the efficacy of interpersonal communication (IPC) in health programmes in Kenya. Consequently, little is documented on barriers to IPC in the implementation of health interventions. We examined specific potential barriers to IPC as an integral device in the implementation of the voluntary medical male circumcision (VMMC) programme in Siaya, Kenya. We used a mixed-methods sequential cross-sectional research design, and the multi-stage sampling technique - combining purposive and chain referral sampling procedures to arrive at the desired samples. Two questionnaires were administered on 370 male residents of Bondo and Rarieda in Siaya; and on 35 implementers of the programme in the two sub-counties. Further, we interviewed five managers from the implementing agencies. We used descriptive and inferential statistics to analyse quantitative data, and presented the findings through text and tables, while qualitative data were analysed through the description, analysis and interpretation process. The findings show time constraints as a significant barrier chiefly from the viewpoint of the operational staff, who admitted lacking time for meaningful interactions with their clients to fully explain issues raised for desired mutual understanding. Culture, in its various forms, has a significant negative cross-cutting bearing on provider-client interactions, while provider-client language difference, coupled with service providers' attitude and jargons had a potential negative effect on the VMMC programme's final outcome, at least from the clients' perspective. We recommend full integration of IPC in healthcare management. Communication training should be accorded its due prominence, both in terms of scope and depth, in all heath training institutions. We further vouch for service provider cultural competence to enhance understanding. IPC can play a crucial role in healthcare management in Kenya due to its ability to facilitate important provider-client transaction, particularly in the largely oral rural resource-deprived populations, which lack adequate access to mass communication media. This study has discussed a raft of potential barriers to IPC, and provides significant insights to planners and managers of management of health programmes and interventions.
\end{abstract}

Keywords: Siaya, Kenya; healthcare; interpersonal communication; barriers; cultural nuances; voluntary male circumcision.

DOI: $10.7176 / \mathrm{JHMN} / 72-10$

Publication date:March $31^{\text {st }} 2020$

\section{Background}

Kenya ranks among the world's highest Human Immunodeficiency Virus (HIV) epidemic burden countries, with about 1.6 million people in the country living with HIV and about 46,000 new infections across all ages in 2018 (Avert, 2018). The epidemic is geographically diverse, ranging from a high prevalence of 21 percent in Siaya, $20.7 \%$ in Homa Bay, $16.3 \%$ in Kisumu and 13.3\% in Migori - all in the Lake Victoria region of western Kenya, to a low prevalence of $0.8 \%$ in Garissa, $0.2 \%$ in Mandera and $0.1 \%$ in Wajir respectively - all in Kenya's north eastern region (Ministry of Health, 2018). With the highest prevalence rate nationally at 21 percent in 2017 (Avert, 2018) Siaya County accounted for 123,107 of the 1,493,382 HIV positive Kenyans, 4,039 of the 52,767 new infections in the country and 2,062 of the national total of 28,214 AIDS related deaths.

In light of substantial evidence that male circumcision significantly reduces a man's risk of acquiring HIV during sex and developing penile cancer (Auvert et al., 2005; Gray et al., 2007), and further proof that male circumcision is capable of protecting women against cervical cancer, cervical dysplasia, herpes simplex virus type 2, chlamydia, syphilis and human papillomavirus among other sex-related diseases, Kenya launched the Voluntary Medical Male Circumcision (VMMC) for HIV Prevention programme in 2008, aiming to achieve a projected universal coverage of 80 percent by 2013 . Kenya, thus, became one of the 14 countries in Eastern and Southern Africa to incorporate VMMC as a component of their national HIV/AIDS prevention programmes (World Health Organization, 2013). All these countries, known in the UNAIDS circles as priority countries, have high prevalence of HIV and a corresponding low incidence of male circumcision. In Kenya, regions with the highest prevalence of 
uncircumcised adult males, which also had the highest HIV prevalence, became the priority regions for the implementation of VMMC (Odhiambo, et al., 2012), Siaya County was one of them. At $21.0 \%$, the county leads in HIV/AIDS prevalence, far above the national prevalence at of 4.9\% (Ministry of Health, 2018). Siaya is found in the Lake Victoria region of western Kenya, and is predominantly inhabited by the traditionally non-circumcising Luo community. It is estimated that nearly half of all uncircumcised men are found in this region, where circumcision prevalence is only $48.2 \%$ against the national average of $85 \%$ (National AIDS Control Council (2018).

However, while VMMC has been embraced with considerable enthusiasm in some quarters, researchers (e.g. Bailey et al., 2001) warn that studies are just beginning, with significant contradicting findings that call for care. KIPRA (2004: 17) says VMMC is "too controversial an issue to be settled by studies alone", arguing that being circumcised is not a shield from HIV infection, since in some communities, circumcision rituals subtly encourage new initiates to seek sexual encounters as proof of their manhood. Thus if VMMC is to be promoted, people should be given sufficient and correct information on HIV prevention to safeguard them from developing a false sense of security and engaging in risky behavior, a consideration that make a well thought out communication programme with the potential to carry the intended interlocutors along, an inevitable component of the VMMC. Interpersonal communication (IPC) is acknowledged as a vital component in fostering attitude and behaviour change or adoption, and a central pillar of health communication owing to its unique features, which enable it to engender compliance with key behaviour adaptation elements as well as deal with issues of cultural conflicts, discrimination and stigma (Rogers \& Storey, 1987; Schiavo, 2013). De Negri et al (2006) identify it as crucial tool in healthcare because of its ability to engender, among other things, positive client-provider rapport; client disclosure of sufficient information for accurate diagnosis; appropriate and acceptable treatment or action; clear client understanding of their condition and prescribed course of action; and the commitment by both parties to fulfill their roles in the dyadic relationship during treatment and follow-up care. Regarding HIV, Siaya presents an apparent mismatch between knowledge and practice in that, while knowledge on HIV/AIDS is very high, averaging above 90 percent, (Kenya National Bureau of Statistics, 2013) corresponding action is very low, a scenario that Rogers (1995) refers to as knowledge attitude and practice gap. Diffusion theorists aver that, although many people tend to rely on mass media to learn about new ideas, they depend on interpersonal networks to move from knowledge to trial, continued practice of a new behaviour, and sustained demand creation (de Negri, et al., 1997).

Studies so far done in Kenya on the role of communication in the health programmes in general and VMMC in particular, have focused chiefly on the mass media (Odhiambo et al., 2012). Despite its popularity in health campaigns, mass media have been shown to have major flaws when it comes to dealing with sensitive issues that transcend the boundaries of health, such as culture, sexuality and stigma (Teixera et al., 2012). Although IPC is acknowledged as a crucial component of health communication, its efficacy or specific achievements in the overall health outcomes cannot be stated with certainty as research in this area is scanty (Cossette, 2005). Equally sparse is research on barriers to IPC in the implementation of health interventions in Kenya. While elsewhere studies have reported poor physician-patient relationships (McCabe et al., 2000; Jangland et al., 2009), and suggested various causes of such poor communication specific to healthcare, particularly to anti-HIV interventions, there is an apparent paucity of similar studies in the Kenyan context. It remains clear, nonetheless, that provider-client relationship in healthcare is a delicate balancing act, fraught with many inhibitions, some outside the strict domains of medical service. This study, thus, looked into health communication from the perspective of barriers to providerclient interaction.

\subsection{Objective of the study}

This study set out to determine specific barriers to effective interpersonal communication among various players in the voluntary medical male circumcision in Siaya County of Kenya.

\section{Methods and materials}

This study employed the cross-sectional design with a mixed-methods approach comprising quantitative and qualitative data collection techniques. We adopted a multi-stage sampling technique, first of research locations and, secondly, of participants. Purposive sampling was used to select the county specific sub-counties. Within the selected sub-counties, proportionate sampling was employed to obtain the desired cases. Three sets of participants constituted the sample frame. The first group consisted of men aged 18 to 50 years, drawn chiefly from the local fishing community, living within Bondo and Rarieda sub-counties. The second group comprised the operational health workers implementing the programme. The final group comprised officials of the agencies implementing the programme in Siaya. We used chain-referral sampling to get the respondents for the first two groups. Further, we purposively sampled for the third group, since the targeted participants were known. As regards target clients, a total of 251 male residents of the selected two sub-counties filled and returned the questionnaire, translating to a response rate of $67.47 \%$. At the same time, all the selected 35 members of staff (representing half of the total number) of the VMMC implementing agencies in the operational cadre filled and returned the questionnaire. We 
conducted five key informant interviews, using a semi-structured interview guide, with managerial staff of the two implementing agencies, namely, Centre for Health Solutions, a non-governmental organisation, and the Ministry of Health. Questionnaires returned from the field were coded and keyed into SPSS computer software for analysis, and data screened using the sort functions. Descriptive statistical analysis was applied to quantitative data collected from two respondent categories, namely the operational health staff in the field who interact with the clients and perform the operations, and the male VMMC clients in the two sub counties under the study. First, we developed a data code sheet and transferred data to IBM SPSS Statistics 22 computer software. Secondly, we undertook data cleaning prior to analysis to identify outliers and remove errors in the data feeding process. The data was then analysed using descriptive statistics such as frequency distribution, percentages, averages and mean values.

For qualitative data, a step-by-step data analysis was done, first transcribing the recordings verbatim then reading through transcriptions and field notes, thus availing ourselves of this immersion process to better feel and understand the data, and note emerging patterns for coding. We employed the inductive approach to code and organise data into categories and themes. Codes were assigned to the various segments of data to tease out emerging patterns, which were then merged to form various categories. The field notes were also used to complement the transcribed text emanating from the audio recordings. The obtained codes were classified to reflect similarities and differences in categories before linking and merging them into common thematic outlines. Themes were continually compared and assessed by viewing the causal conditions, context, and interactions. Unidentified texts that required further clarification were marked for counterchecking from the field notes and the transcribed text checked before being related to the relevant themes. Through the induction process, data were interpreted according to the identified themes. Organised narrative texts that include use of verbatim quotations were used to further authenticate the findings.

\subsection{Ethical clearances}

Prior to embarking on data collection, we obtained an ethical clearance from the Ethics Committee of Masinde Muliro University of Science and Technology, and a research permit from the National Commission for Science, Technology and Innovation. Further, we secured the approvals of the following authorities to collect data in their areas of jurisdiction: County Commissioner, Siaya; County Director of Education, Siaya; Deputy County Commissioner, Maranda; and National Director, Centre for Health Solutions. At the same time we ensured that all participants had full disclosure on the study through verbal explanation and the approved consent form. In view of the sensitivity of some socio-cultural and health issues on HIV/AIDS and circumcision, the participants were assured of strict confidentiality during and after the data collection process.

\subsection{Results}

\subsection{Demographic data}

\subsubsection{Economic activity and income}

From the above findings, the majority of the respondents were fishermen, accounting for 64.2 per cent of all the respondents. The rest of the respondents, represented by a consolidated 35.8, were engaged in economic activities that support fishing such as transport, sale of fishing gear, fish loading, among other. The findings further show that the respondents were primarily from resource-deprived backgrounds with a consolidated 68.6 percent earning USD100 and below per month, while only 28.3 per cent fell in the US $\$ 100$ to US $\$ 150$ bracket, and a paltry 3.1 percent above US\$150.

\subsubsection{County and community of origin}

The study established that majority of the clients were from Bondo Sub-county (45.6\%) and Rarieda (34.4\%), which were the loci of this study. The remaining four sub-counties of Siaya, namely Alego Usonga, Gem, Ugunja and Ugenya, had under 10 per cent, while those from outside Siaya County accounted for $11.1 \%$. The establishment of the service providers' ethnic identity, hence cultural orientation, was important because of the possible effect of cultural differences between health intervention interactants on the final health outcome.

\subsubsection{Age distribution}

On age aggregates, we established that majority (53.8\%) of the respondents were between 28 and 37 years, followed by those aged between 18 and 27 years, representing 28.7 per cent. 38 to 47 years accounted for 12.6 per cent. The remaining age brackets accounted for below 10 per cent. The respondents' marital status indicated that 29.4 per cent of them were single, while the bulk were married, accounting for 49.0 per cent. Those that were separated represented up to 9.1 per cent, while those who were divorced or widowed were 4.9 per cent and 2.1 percent respectively. For service providers, the respondents were distributed across all ages with the middle age bracket of 29 to 39 years taking the bulk of respondents at 54.3 percent, while the bottom and top age brackets of 18 to 28 years and 40 to 50 years almost equally sharing the rest, at 25.7 percent and 20 percent. The service providers' age distribution was in congruence with that of the target clients, with respondents aged between 28 and 37 years account for 53.8 per cent. 


\subsubsection{Level of education and language competence}

We establish that 50.3 per cent of the respondents had primary as their highest level of education, 34.3 per cent had gone up to secondary school level, 7.7 per cent were of college level and only 3.5 per cent had at least a university level of education. At the same time, the client respondents were found to be most competent in Dholuo language with 83.8 per cent indicating that they were very competent. Their competence in English and Kiswahili languages was evenly spread between a high of 36.0 per cent and a low of 1.9 per cent. For service providers, we found that the highest concentration of education was at the college level with 51.5 percent being college graduates. Secondary school graduates accounted for 36.1 percent, while primary and university levels of education accounted for low numbers of 6.1 percent and 6.3 percent respectively. This distribution is at variance with the target clients' education levels, where the highest concentration was at primary level of education with 50.3 percent, followed by secondary, at 34.4 percent. The findings further show that the programme's implementers were generally competent in all the three languages tested, namely Kiswahil, a lingua france spoken predominantly in east and central Africa; Dholuo, a dialect of the Luo community of Kenya, Uganda and Tanzania and Uganda; and English, as shown in Figure 2 below. However, comptence in English was the highest, with 63.6 percent and 33.5 percent saying they were "competent" and "very competent" respectively. Dholuo showed the lowest level of competence. Up to 38.4 percent said they were compentent and 35.2 percent admitted they were barely competent, while only 17 percent said they were "very competent."

\begin{tabular}{|c|c|c|}
\hline Variable & & $\%$ \\
\hline \multirow{6}{*}{$\begin{array}{l}\text { Occupation } \\
\text { Source of income }\end{array}$} & Student & $0.7 \%$ \\
\hline & Fisherman & $64.2 \%$ \\
\hline & Businessman & $16.8 \%$ \\
\hline & Government employee & $6.6 \%$ \\
\hline & Private business employee & $8.8 \%$ \\
\hline & Others & $3.0 \%$ \\
\hline \multirow{4}{*}{$\begin{array}{l}\text { Sub-county of } \\
\text { origin }\end{array}$} & Bondo & $45.6 \%$ \\
\hline & Rarieda & $34.4 \%$ \\
\hline & Other Siaya sub-counties & $8.8 \%$ \\
\hline & Outside Siaya County & $11.1 \%$ \\
\hline \multirow{4}{*}{ Age } & $18-27$ & $28.7 \%$ \\
\hline & $28-37$ & $53.8 \%$ \\
\hline & $38-47$ & $12.6 \%$ \\
\hline & $48-57$ & $4.9 \%$ \\
\hline \multirow{5}{*}{ Marital status } & Single & $35.4 \%$ \\
\hline & Married & $43.0 \%$ \\
\hline & Separated & $9.1 \%$ \\
\hline & Divorced & $4.9 \%$ \\
\hline & Widowed & $2.1 \%$ \\
\hline \multirow{5}{*}{$\begin{array}{l}\text { Highest level of } \\
\text { education }\end{array}$} & University & $3.5 \%$ \\
\hline & Secondary & $34.3 \%$ \\
\hline & Primary & $50.3 \%$ \\
\hline & College & $7.7 \%$ \\
\hline & None & $4.2 \%$ \\
\hline
\end{tabular}


Table 2: Respondents' demography - service providers

\begin{tabular}{lll} 
Variable & & \% \\
\hline \multirow{2}{*}{ Gender } & Male & $52.0 \%$ \\
& Female & $48.0 \%$ \\
\hline \multirow{5}{*}{ Marital Status } & $18-28$ & $25.7 \%$ \\
& $29-39$ & $54.3 \%$ \\
& $40-50$ & $20.0 \%$ \\
\hline \multirow{2}{*}{ Ethnic origin } & Single & $38.6 \%$ \\
& Married & $53.3 \%$ \\
& Separated & $4.9 \%$ \\
& Divorced & $0.0 \%$ \\
& Widowed & $3.2 \%$ \\
\hline \multirow{2}{*}{ Level of Education } & Luo & $59.4 \%$ \\
& Other & $41.6 \%$ \\
\hline & Primary & $6.1 \%$ \\
& Secondary & $36.2 \%$ \\
& College & $51.5 \%$ \\
& University & $6.2 \%$ \\
\hline
\end{tabular}

\subsection{Specific barriers to interpersonal communication}

The thrust of this study was to determine whether there were factors that could prevent interpersonal communication from playing an effective facilitative role in ensuring success of voluntary medical male circumcision as an invention against HIV. Specific factors were identified as possible barriers to interpersonal interaction between or among various key players, including programme implementers, target clients, local leaders and clients' kin and peers. The barriers identified were time constraints; language and education differences, cultural factors, age and gender differences, and provider-client interaction environment.

\subsubsection{Time constraints}

The study sought to establish if, from the perspective of the service providers, the time allocated for different IPC strategies was adequate. For peer education, 59.8 percent of respondents thought the time allocated was either "not adequate" or "not adequate at all," while 40.2 per cent were of the view that the time was either "adequate" or "very adequate." A total of 55.5 percent of the respondents were of the view that the time allocated for community sensitisation was not adequate while 44.5 thought it was adequate.

However, on pre-circumcision counselling, up to 56.7 percent agreed that the allocated time was adequate, while the rest $(43.3 \%)$ thought otherwise. In the case of time assigned for post circumcision counselling, the respondents were divided more or less equally, with 51.1 percent saying the time was adequate, while 49.9 did not agree (Table 3).

Table 3: Views on time allocated for various IPC strategies

\begin{tabular}{|c|c|c|c|c|}
\hline & 总 & 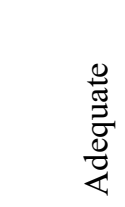 & 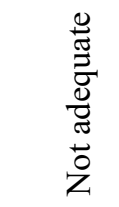 & 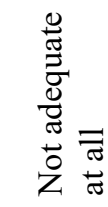 \\
\hline Peer education & $19.5 \%$ & $20.7 \%$ & $40.9 \%$ & $18.9 \%$ \\
\hline Community sensitisation & $5.9 \%$ & $22.6 \%$ & $53.6 \%$ & $17.9 \%$ \\
\hline Pre circumcision counseling & $26.5 \%$ & $30.2 \%$ & $27.4 \%$ & $11.9 \%$ \\
\hline Post-circumcision counseling & $14.7 \%$ & $36.4 \%$ & $30.7 \%$ & $18.2 \%$ \\
\hline
\end{tabular}

We further sought to know how time constraints affected the general provider-client consultations. The findings, as shown in Table 4 below, indicate that inadequacy of time was a major barrier to provider-client interpersonal interaction, with 70.7 percent of the respondents saying that lack of time was "to a large extent" and "to a very large extent" a barrier to effective communication. However, 20.2 percent thought time constraints ere a barrier only "to a limited extent." Only 9.1 per cent of the respondents thought it was a barrier "to a large extent" and "to a very limited extent" respectively. The target clients, on their part, were of a different opinion with most saying time constraints was not a major hindrance to their interaction. A total of 34.2 per cent said time shortage was a barrier only "to a limited extent," while and 20.0 per cent thought it was "to a very limited extent."

\subsubsection{Language difference and levels of education}

A total of 63.3 percent of surveyed service providers said that language difference between them and their clients was a barrier to their interaction either "to a large extent" or "to a very large extent." Only 26.7 of service providers 
thought that language difference was not a barrier. A total of 63 percent of surveyed service providers thought that interpersonal communication would be hampered by clients' low level of education. Clients, on their part also agreed that language difference was a barrier to communication, with 65.3 percent of them saying it would hamper interaction "to a large extent" or "to a very large extent." Only 24.7 thought otherwise. They were also in agreement with the service providers' view that their (clients') low level of education did not augur well for interaction and understanding, accepting that low education made it difficult to have meaningful interpersonal communication $(69.2 \%)$

\subsubsection{Age and gender differences}

The service providers concurred with their target clients on age and gender differences between them being a barrier to their interaction, with 62.9 percent being of the view that age difference was a major hindrance to their communication with VMMC clients, while 62.4 percent thought the same about gender difference. For target clients, 65.5 percent of the respondents agreed that provider-client age difference was a barrier, with only 34.5 percent disagreeing, as shown in Table 5 below:

\subsubsection{Service providers' attitude and technical jargons}

Another reported barrier to communication was the service providers' attitude, where 69.1 per cent of the target clients said that service providers" "patronising attitude" hindered consultation. Asked about the service providers" language, 42.6 per cent of the respondents said that their technical medical jargon was a barrier to "a large extent" while 29.0 per cent said it was to "a very large extent. Thus, a total of 71.6 per cent of the respondents agreed that the service providers' technical language in the VMMC campaign was a barrier to effective interpersonal communication. However, asked whether their attitude was "patronising", majorly of the surveyed staff were of the opinion that this was not true, with 57.9 percent and 36.2 percent saying their attitude could be a barrier only "to a very limited extent" and "to a limited extent" respectively. However, they were divided in opinion as to whether their technical jargon could hinder effective communication with the target clients with no training in health matters, with 50.1 percent saying their technical medical language could not help facilitate interaction, while 49.9 percent disagreed.

\subsubsection{Interpersonal communication environment}

Another area where the service providers and target agreed largely on whether it was a barrier to interpersonal communication in healthcare was the state of cleanliness of the facilities where health consultations take place. Up to 70.2 per cent of the clients agreed that the environment of the consultation was a matter of concern. Only 29.8 thought it was not a barrier. On their part, 44.5 percent and 29.4 percent of the surveyed service providers said unhygienic environment had negative effect on interpersonal interaction between them and their clients "to a large extent" and "to a very large extent" respectively

\section{Table 4: Barriers to interpersonal communication according to service providers}

$\begin{array}{llll} & & & \\ & & & \\ & & & \end{array}$


Table 5: Barriers to interpersonal communication according to target clients

$\begin{array}{llll} & & & \end{array}$

\subsubsection{Cultural factors as barriers to IPC}

When asked about cultural beliefs and client-provider cultural differences as a factor, target clients who agreed that the service providers' failure to appreciate their (clients') culture was a hindrance to the VMMC campaign, were in the majority, at 37.1 percent saying "to a large extent" and 31.4 percent saying "to a very large extent." Only 31.5 per cent thought differently. Further, we sought the service providers' view regarding the possible difficulty in implementing VMMC as a result of the Luo community's cultural beliefs regarding HIV/AIDS and male circumcision, 49.5 per cent of the respondents agreed, 22.2 per cent answered "strongly agree." Only 19.2 per cent and 9.1 respectively "did not agree" and "did not agree at all."

\subsection{Discussion}

Effective consultations with health service seekers demand not only good communication skills, but also personal awareness of the likely barriers to effective communication (Maguire, 1985). The context and content of communication in healthcare often generate challenging and highly charged emotions resulting in poor or total lack of communication between healthcare providers and their clients. Effective consultations with patients demand not only good communication skills, but also personal awareness of the likely barriers to effective communication. Corcoran (2007) argues that wrong content of health communication delivered in unsuitable context often generate challenging emotions, resulting in poor or lack of provider-client interaction, and, eventually, loss of confidence. A number of factors contribute to poor communication that gives way to such lack of understanding, usually with negative effects on health outcomes. According to Norouzinia and others (2016) suggest, the first step in addressing the challenges related to provider-client communication is the unpacking and understanding the complex two-sided (provider-client) relationship, a relationship whose success is dependent on the effective interaction in the dyad (Park \& Song, 2005). This study focused on specific factors and examined, from the perspective of both the health workers and clients, their potential to hamper IPC in the implementation of VMMC programme in Siaya County.

\subsection{Time constraints}

Time constraints constitute a major barrier especially among the operational staff who have to distribute their limited time to a large number of clients. The majority $(70.7 \%)$ of service providers confessed that inadequacy of time made it difficult to give their full attention to clients, explain in detail issues raised and create an appropriate atmosphere of mutual understanding. Most of the field staff have tight targets to meet, with each of them allocated a specific number of target clients to serve within a given time slot. This puts a major constraint on them, leaving them with no ample time with each target client. We established that the bulk of the mobilisers, who included peer educators and community health volunteers, are not on full time employment of the VMMC implementing agencies, and have to share their time between the mobilisation work and their other economic and social engagements, a factor that exacerbates the time constraints. There exists, however, a significant difference in perception about adequacy of time between client and providers. Among the target clients, time is not seen as a key barrier to effective interpersonal communication, with majority (over 66\%) saying time was a barrier only "to a limited extent." These findings are in consonance with those of Norouziana and others (2016) in their study of the barriers to effective nurse-patient communication, which showed that health workers' viewpoints were at variance with those of their clients, feeling more strongly of time constraints as a barrier to health communication than their clients.

From in-depth interviews with the implementers, we can attribute this discrepancy to the priority that each 
group attaches to the VMMC programme. Whereas the service providers attached utmost priority to the success of the intervention, the clients' focus was on earning their livelihood and anything that came between them and their economic activities was a distraction. Moreover as Schiavo (2013) argues, that the onus to create good understanding in a heath communication dyad rests with the health worker. In general terms, many studies have identified time constraint as a major hindrance to positive health outcomes. During consultation, the clients do not get enough time to present their story and are often interrupted midway (Park \& Song, 2005). From the health service provider's viewpoint, long working hours are often too burdensome to leave time for effective interaction (Maguire, 1985). Yet allowing parties enough time to express their concerns and symptoms is likely to translate into a better provider-patient relationship and to fewer follow-up visits, and shorter, more focused, interactions, an ideal that is hampered by the reality that primary health personnel are expected to deal with an increasing number of patients to satisfy healthcare policies in the face of cost-cutting interventions.

\subsection{Cultural Factors}

Culture, with its subtle nuances surrounding age, gender in relation to sexuality, diseases and human body parts, was also found to have a significant cross-cutting bearing on provider-client interactions. A number of both clients and service providers surveyed admitted that the culturally non-circumcising nature of the Luo community, coupled with their strong beliefs on AIDS as a disease, made conversations on HIV/AIDS and VMMC rather complicated. Moreover, family relations also had a significant bearing on the communication, where service provider reported complex beliefs pertaining to sexuality within the wider family circles. For instance, the key informants told us that the decision to circumcise a boy, particularly in the rural setting, did not lie with the parents alone; on the contrary, the boy's paternal grandmother had to give her consent since, traditionally speaking, the boy is her "husband," and therefore she is important in the boy's life, and thus her assent is needed for VMMC to take place. This finding is in consonance with Fishbein and Capella's (2006) theoretical standpoint, which advises spreading of health decision across the "significant others."

We also found culture to touch on age, as young mobilisers found it difficult to discuss sexual issues with people far above their age. Majority of both the service providers and clients $(69.9 \%$ and $65.3 \%$ respectively) agreed that age was a major factor. In their study on factors affecting effective communication about sexual and reproductive health issues between parents and adolescents in South Africa, Motsomi and others (2006) found that cultural beliefs act as an inhibiter in mediating and addressing issues of sex and reproductive health. Parents or people of the same age find it difficult to speak openly to the youth on those matters because, according to the respondents: "our culture does not allow us as parents to directly talk to our children about issues of sexual and reproductive health... Matters to do with sex are traditionally a taboo in our culture, such are private subjects, not befitting public discourse" (p.5). The finding has consistence with other studies which found that issues of sexuality and reproductive health are culturally sensitive hence are often not openly discussed across ages, particularly in communities where cultural beliefs are still intact (Botchway, 2004; Guilamo-Ramos, 2008). On their part, Park and Song (2005) found generation gap as a barrier to communication between health service providers and clients. Key informant interviews revealed that the implementers were aware of these problems, and were working to resolve them by targeting age appropriate communication strategies, with emphasis age when it comes to peer-based communication.

The same applies to gender difference where 61 percent and 69.3 percent of the providers and clients respectively were of the view that discussion on matters to do with sexuality was complicated across gender, and was a hindrance to the communication campaign for VMMC. The findings are consistent with those by Wamoyi and others (2011) on parent-child communication about sexuality in Tanzania where such communication about sex and reproductive health was uncommon, and if it happened, was mainly delivered by mothers and rarely fathers. The situation in our study was made complicated by the fact that in the case of the VMMC campaign the communication is supposed to be led by the young women who are leading the mobilisation and counseling programmes. This is because, as Lesch and Kruger (2005) posit, such discussions, if they happens, are invariably parent-led. For the fathers, in the rare occasion that they engage their daughters, they communicate through threats and warnings (Wamoyi et al., 2011).

A considerable number of those surveyed from both the provider and client spectra of the study, representing over 68 percent on each side believed that cultural differences in general was a major hindrance to effective health communication, a view that supports Dodd's (1998) assertion that perceived cultural differences alone can be a hindrance to successful communication outcome. Bakić-Mirić and others (2012) cite diversity of cultural backgrounds as one of the causes of unclear communication engagements, while Norouzinai and others (2016) aver that patients are also less acceptant of health service providers with different languages and cultures. Aware of this, the VMMC programme implementers in interviewed informed us that in order to deal with the general cultural differences as a result of differing ethnic origin, their recruitment, particularly for the mobilisers and other filed officers, was skewed towards recruiting mobilisers mainly from the Luo community, which the bulk of the target clients hail from. 
However, one area where the findings of this study disagree with earlier theoretical standpoint and empirical findings is where the communication focus should be placed. Dutta-Bergman (2009) posits that when dealing with a culturally sensitive health related behaviour like VMMC, health campaigners find that decision making requires more than the individual target clients, but the wider community whose tacit or explicit consent is necessary. In his study on culture and health decisions among Thai and the Pilipino, where young men visit brothels as a rite of passage, Brown (2000) found that attitudes and beliefs regarding visits to brothels were not located in the individual as much as they were in the broader community. On the contrary, the bulk of respondents in this study said they would not be influenced by community leaders or elders in their decision to go for the "cut." Instead the sphere of influence was limited to wife and the narrow circle of friends, what Fishbein and Capella (2006) call "significant others." This study hold the view that the low level of community influence is attributable to the influence of modernity urbanisation and inter-generational conflicts, mind that the study was conducted among fairly young people in largely urban centres, where the youth and those $n$ their middle age were significantly detached from cultural grip of the elderly people as obtains in the rural areas.

\subsection{Attitude and medical jargon}

On provider-client relationships, the majority of the clients surveyed thought the service providers "patronising" attitude, coupled with their technical medical jargon were a hindrance to provider-client interaction. However, the majority of service providers reported that these twin issues were not a problem in their interaction with their clients, only agreeing that the provider-client language difference was an obvious problem. This divergence in opinions would be expected because, while the clients could be quick to point out what they saw as mistakes on the part of their interlocutors, it might be lost on the latter that their attitude is not pleasant. Furthermore, concerning technical jargon, the providers might not know that they were using jargon since this is their daily mode of communication among themselves. These findings are consistent with those of other studies (Mrayyan, 2007), which have identified language nature, type and jargons, providers' attitude and lack of cooperation from either, as major hindrances to positive transaction. Specifically, service provider's unfamiliarity with the client's native language has been mentioned in many studies as a communication barrier (Anoosheh et al., 2009; Li et al., 2012), with the observation that if there is a difference in spoken language, effective communication cannot be established. Even non-verbal communication in different cultures may have different interpretations (Norouzinia, 2016).

\subsection{Level of education and language difference}

Another area where the providers and the clients were in agreement as a possible barrier to their interaction was level of education. A number of clients, particularly those with low education levels, thought that some health workers looked down upon them because of their level of education, while the providers, although not accepting the clients' claim that they looked down upon their clients, said the problem was caused by the clients' failure to understand "some basic" health information and issues. This finding is in agreement with another study conducted in Mangochi, Malawi in which it was observed that education gap between the two interactants was a key barrier in accessing maternal services (Seljeskog et al., 2006). To address this, (Madula et al., 2018) propose that providers should offer patient clear and concise means to understand health information regardless of the latter' education level. Thus, communication by healthcare providers has to be designed for the average or illiterate person to understand and must be put in simple and appropriate language (Bohren et al., 2014).

\subsection{Conclusion and recommendations}

It is clear that factors such as time allocated various communication activities, and democratic profiles like age, gender, and education of the intended beneficiaries vis-à-viz those of the health service providers have a direct bearing on the outcome of interpersonal communication programmes. In this study we have found that time constraints and culture, with its subtle nuances surrounding age, gender in relation to sexuality, diseases and human body parts are some of the most significant barriers to interpersonal communication in the implementation of voluntary medical male circumcision. Besides, the attitude of the programme's implementers, their technical medical jargon and the target clients' poor education a major impediment to the interaction. In view of the foregoing we recommend communication in general and interpersonal communication in particular be integrated in the general spectrum of healthcare management. Further, communication training should be accorded its due prominence, both in scope and depth, in all heath training institutions. We further vouch for service provider cultural competence among the service providers in order to bolster their interaction and understanding with the programme's target clients and "significant others."

\subsection{The Study's Contributions to Knowledge}

Communication has gained considerable traction in healthcare management and is now being mainstreamed in an increasing number of health programmes in Kenya, with interpersonal communication claiming significant 
recognition due to its ability to facilitate meaningful provider-client transition particularly in largely oral rural resource-deprived population, which lack adequate access to mass media facilities. This study has unpacked a raft of potential barriers to interpersonal communication, which will go a long way in providing a significant insights to those involved in the planning and management of health programmes.

\section{References}

Anoosheh, M., Zarkhah, S., Faghihzadeh, S. \& Vaismoradi, M. (2009) Nurse-patient communication barriers in Iranian nursing. International Nursing Review. 2009;56(2):243-249. http://dx.doi.org/10.1111/j.14667657.2008.00697.x . [PubMed] [Google Scholar]

Auvert, B., Taljaard, D., Lagarde, E., Sobngwi-Tambekou, J., Re'mi Sitta, R. \& Puren, A. (2005) Randomized, Controlled Intervention Trial of Male Circumcision for Reduction of HIV Infection Risk: The ANRS 1265 Trial. PLOS Med, 2(11):1112. https://journals.plos.org/plosmedicine/article?id=10.1371/journal.pmed.0020298

Avert (2018) HIV and AIDS in Kenya https://www.avert.org/professionals/hiv-around-world/sub-saharanafrica/kenya

Bailey, R., Plummer, F., \& Stephen, M. (2001) Male circumcision and HIV prevention: Current knowledge and future research directions. The Lancet Infectious Diseases, 1(4): 223.

Bakić-Mirić, N., Gogić, A. \& Bakić, N. (2012) Conceptual Framework for Communicating Health and Illness across Cultures. Vojnosanit Pregl 2012; 69(3): 260-264.

https://pdfs.semanticscholar.org/4296/1da638bb10eb4be0a21d34ee6c468170c20d.pdf

Bohren, M., Hunter, E., Munthe-Kaas, H., Souza, J., Vogel, J. \& Gülmezoglu, A. (2014) Facilitators and barriers to facility-based delivery in low- and mid-income countries: a qualitative evidence synthesis. Reproductive Health. 11:71. https://doi.org/10.1186/1742-4755-11-71

Botchway, A. T. (2004) Parent and adolescent male's communication about sexuality in the context of HIV/AIDS: a study in Eastern Region of Ghana. MPhil thesis (Unpub): University of Bergen. 26(2):1-122.

Corcoran, Nova (2007) Theories and models in communicating health messages In Nova Corcoran (Ed.) Communicating Health: Strategies for Health Promotion, Sage Publications.

Cossette, S., Cara, C., Ricard, N. \& Pepin, J. (2005) Assessing nurse-patient interactions from a caring perspective: Report of the development and preliminary psychometric testing of the Caring Nurse-Patient Interactions Scale. International Journal of Nursing Studies, 42(6), 673-686. http://dx.doi.org/10.1016/ j.ijnurstu.2004.10.004 [PubMed] [Google Scholar]

De Negri, B. et al. (2006) Improving Interpersonal Communication between Health Care Providers and Clients, Quality Assurance Methodology Refinement Series. USAID: Wisconsin.

Dodd, C. (1998) Dynamics of Intercultural Communication (5th Edition). Boston, MA: McGraw Hill.

Duggan, A. (2006) Understanding Interpersonal Communication Processes Across Health Contexts: Advances in the Last Decade and Challenges for the Next Decade, Journal of Health Communication: International Perspective, 11:1, 93-108, DO1: ncbi.nlm.nih.gov/PubMed/16546921 [PubMed]

Dutta-Bergman, M. (2006) Primary sources of health information: Comparisons in the domain of health attitudes, health cognitions, and health behaviors. Health Communication, 16(3), 273-88.

Fishbein, M. \& Cappella, J. (2006) The Role of Theory in Developing Effective Health Communications. Journal of Communication. DOI: 10.1111/j.1460-2466.2006.00280.x

Gray, R., Kigozi, G., Serwadda, D., Makumbi. F., Watya, S., Nalugoda, F. et al. (2007) Male circumcision for HIV prevention in men in Rakai, Uganda: a randomised trial. Lancet. 24;369 (9562):657-66. https://www.ncbi.nlm.nih.gov/pubmed/17321311

Guilamo-Ramos, V. \& Bouris, A. (2008) Parent-Adolescent Communication about Sexin Latino Families: A Guide for Practitioners.

Hadi, A. (2001). Promoting Health Knowledge through Micro-Credit Programme: Experience of BRAC, Bangladesh. Health Promotion International, 16, 219-227.

Jackson, L., \& Duffy, B. (1998) (Eds.) Health Communication Research. Westport, CT: Greenwood.

Jangland, E. et al. (2009) Patients' and relatives' complaints about encounters and communication in health care: Evidence for quality improvement. Patient Education and Counseling, 75(2), 199-204. http://dx.doi.org/10.1016/j.pec.2008.10.0 [PubMed]

Lesch, E. \& Kruger, L. (2005) Mothers, daughters and sexual agency in one low-income South African Community. Social Science \& Medicine 2005, 61:1072-1082.

Li, H., Ang, E. \& Desley, H. (2012) Nurses' perceptions of the barriers in effective communication with impatient cancer adults in Singapore. Journal of Clinical Nursing. 2012;21(17-18):2647-2658. http://dx.doi.org/10.1111/j.1365-2702.2011.03977.x . [PubMed] [Google Scholar]

Madula, P., Kalembo, F., Yu, H. \& Kaminga, A. (2018) Healthcare provider-patient communication: a qualitative study of women's perceptions during childbirth. Reproductive Health (2018) 15:135 
https://doi.org/10.1186/s12978-018-0580-x

Maguire, P. (1985) Barriers to psychological care of the dying. British Medical Journal, 291, 1711-1713.

McCabe, C. McDowell, J., Cushnaghan, J., Butts, S., Hewlett, S., Stafford, S. et al. (2000) Rheumatology telephone helplines: an activity analysis. Rheumatology; 39:1390-5.

https://academic.oup.com/rheumatology/article/39/12/1390/1784259

Ministry of Health, Kenya (2018) Kenya HIV Estimates Repot 2018

https://nacc.or.ke/wp-content/uploads/2018/11/HIV-estimates-report-Kenya-20182.pdf

Motsomi, K. Chandra Makanjee, C., Basera, T. \& Nyasulu, T. (2016) Factors affecting effective communication about sexual and reproductive health issues between parents and adolescents in zandspruit informal settlement, Johannesburg, South Africa Pan African Medical Journal 25: 120. doi: 10.11604/pamj.2016.25.120.9208

Mrayyan, M. (2007) Nursing practice problems in private hospitals in Jordan: Students' perspectives. Nurse Education in Practice. 7, 82-87

National AIDS Control Council (3018) Kenya Aids Response Progress Report 2018 https://www.lvcthealth.org/wp-content/uploads/2018/11/KARPR-Report_2018.pdf

National AIDS and STI Control Programme (2018) Kenya AIDS Indicator Survey 2017: Final Report. Nairobi, NASCOP. June 2014.

Norouzinia, R., Aghabarari, M., Shiri, M., Karimi, M. \& Samami, E. (2016) Communication Barriers Perceived by Nurses and Patients. Global Journal of Health Science. 8(6): 65-74. doi: 10.5539/gjhs.v8n6p65

Odhiambo, F., Laserson, K., Sewe, M., Hamel, M., Feikin, D., Adazu, K. et al. (2012) Profile: the KEMRI/CDC Health and Demographic Surveillance System--Western Kenya. PubMed 41(4):977-87. doi: 10.1093/ije/dys 108

Park, E. \& Song, M. (2005) Communication barriers perceived by older patients and nurses. International Journal of Nursing Studies, 42(2), 159-166. http://dx.doi.org/10.1016/j.ijnurstu. 2004.06.006

Rogers, E. \& Storey, J. (1987) Communication campaigns. In C. Berger \& S. Chaffee (Eds.), Handbook of communication science (pp. 817-846). Newbury Park, CA: Sage.

Schiavo, R. (2013) Health Communication: From Theory to Practice 2nd Edition, ossey-Bass

Seljeskog, L., Joanne, S. \& Chimango, J. (2006) Factors influencing women's choice of place of delivery in rural Malawi: an explorative study. African Journal of Reproductive Health. 10(3):66

Teixera, R. et al. Carlini, C., Sousa, A., Fernandes, P., Camargo, V., Vogt, C. \& Li, L. (2012). Reporting on HealthRelated Research in Prestigious http://w.w.w.ncbi.nlm.nih.gov/pmc/articles/PMC3297036

Wamoyi, J. Fenwick, A., Urassa, M., Zaba, B. \& Stones, W. (2011) Parent-child communication about sexual and reproductive health in rural Tanzania: Implications for young people's sexual health interventions. BMC Pub Med 11: 106. https://bmcpublichealth.biomedcentral.com/articles/10.1186/1471-2458-11-106

UNAIDS (2013) UNAIDS report on the global AIDS epidemic 2013

UNAIDS (2007) Male Circumcision: Part 3 http://allcircumcision.blogspot.com/2007_07_01_archive.html 